Supporting Information for

\title{
Thermoreversible Ion Gels with Tunable Melting Temperatures from Triblock and Pentablock Copolymers
}

Yiyong $\mathrm{He}^{1}$ and Timothy P. Lodge $\mathrm{L}^{1,2 *}$ 


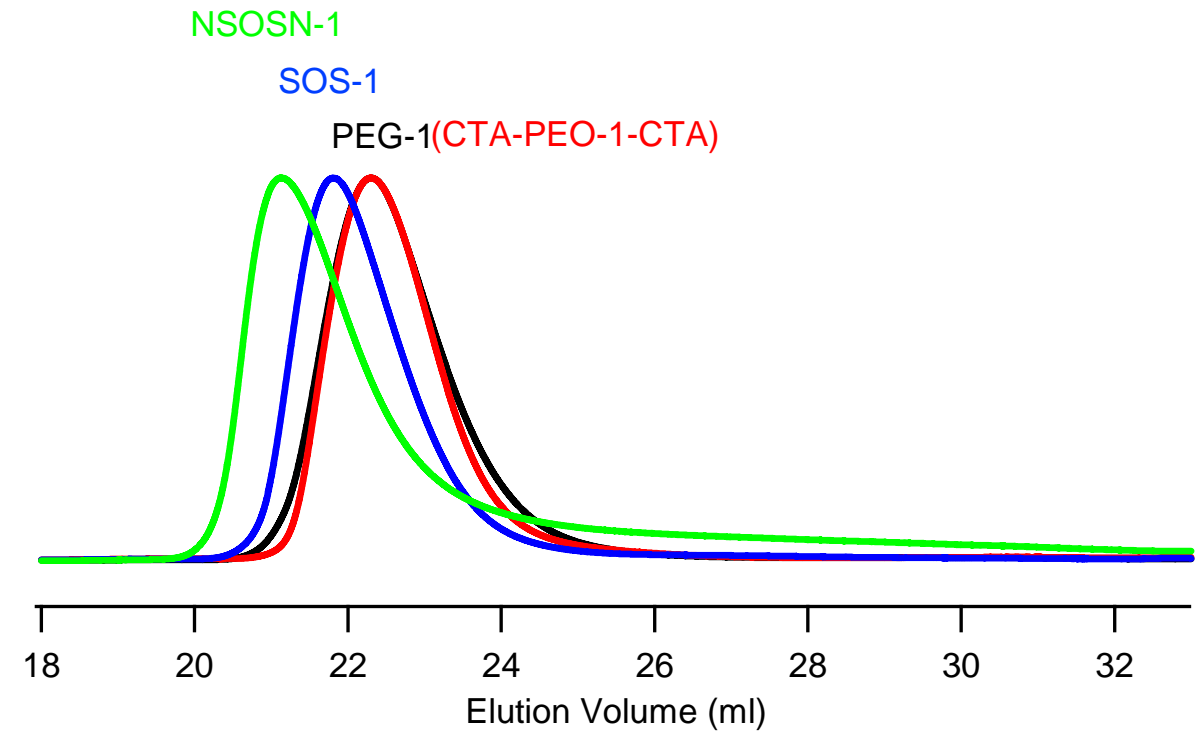

Figure S1. GPC traces of PEG-1 homopolymer, CTA-PEO-1-CTA macroinitiator, SOS-1

triblock copolymer, and NSOSN-1 pentablock copolymer. THF was used as an eluent at a flow rate of $1.0 \mathrm{ml} / \mathrm{min}$. 


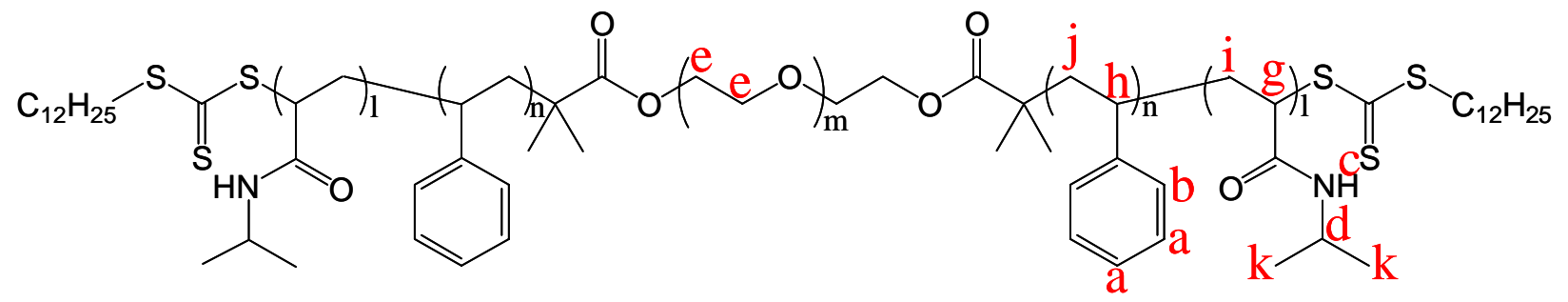

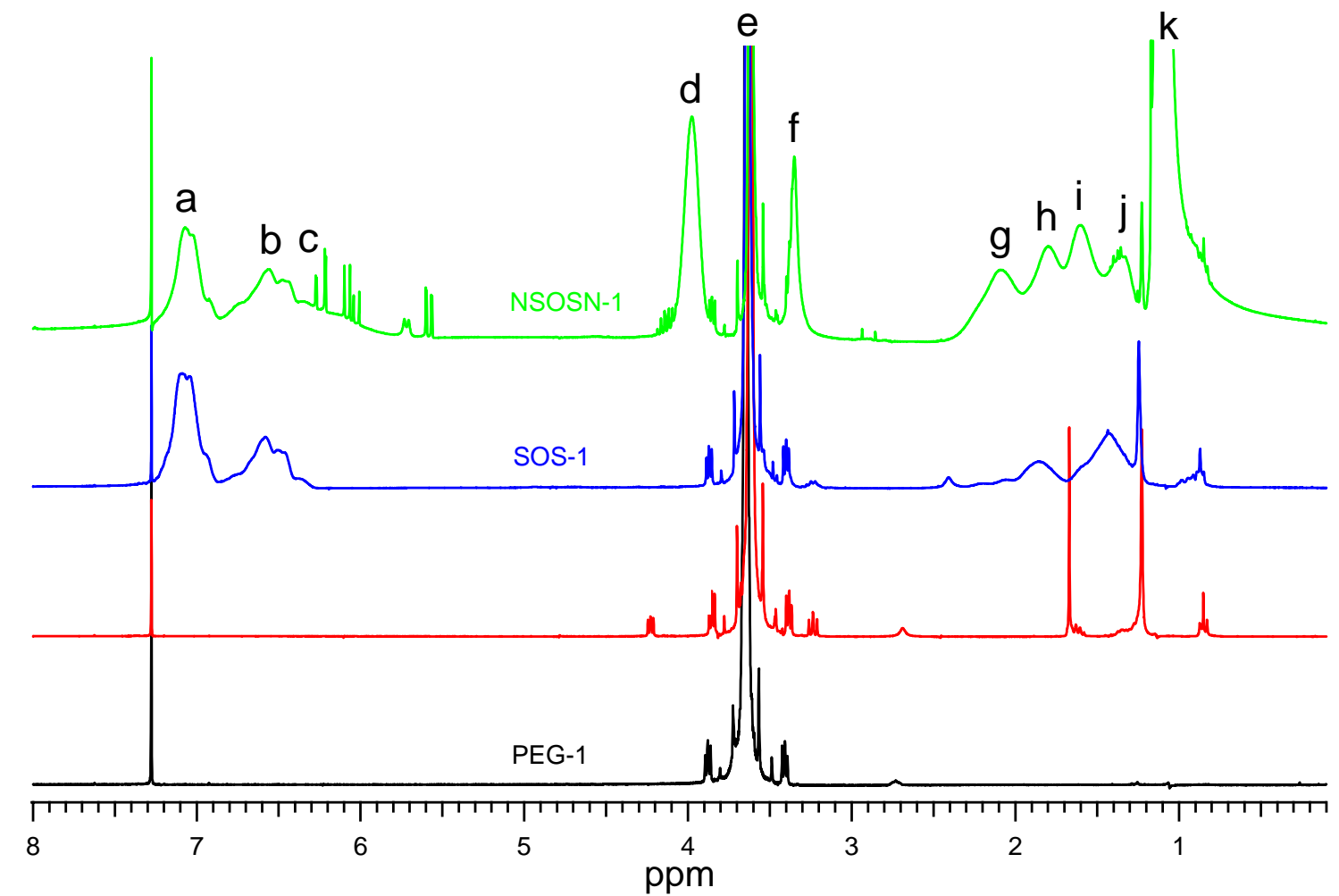

Figure S2. ${ }^{1} \mathrm{H}$ NMR spectra of PEG-1 homopolymer, CTA-PEO-1-CTA macroinitiator, SOS-1 triblock copolymer, and NSOSN-1 pentablock copolymer. The peaks are assigned for the NSOSN-1 pentablock copolymer. (Peak $\mathrm{f}$ is ascribed to residual solvent/impurity.) 


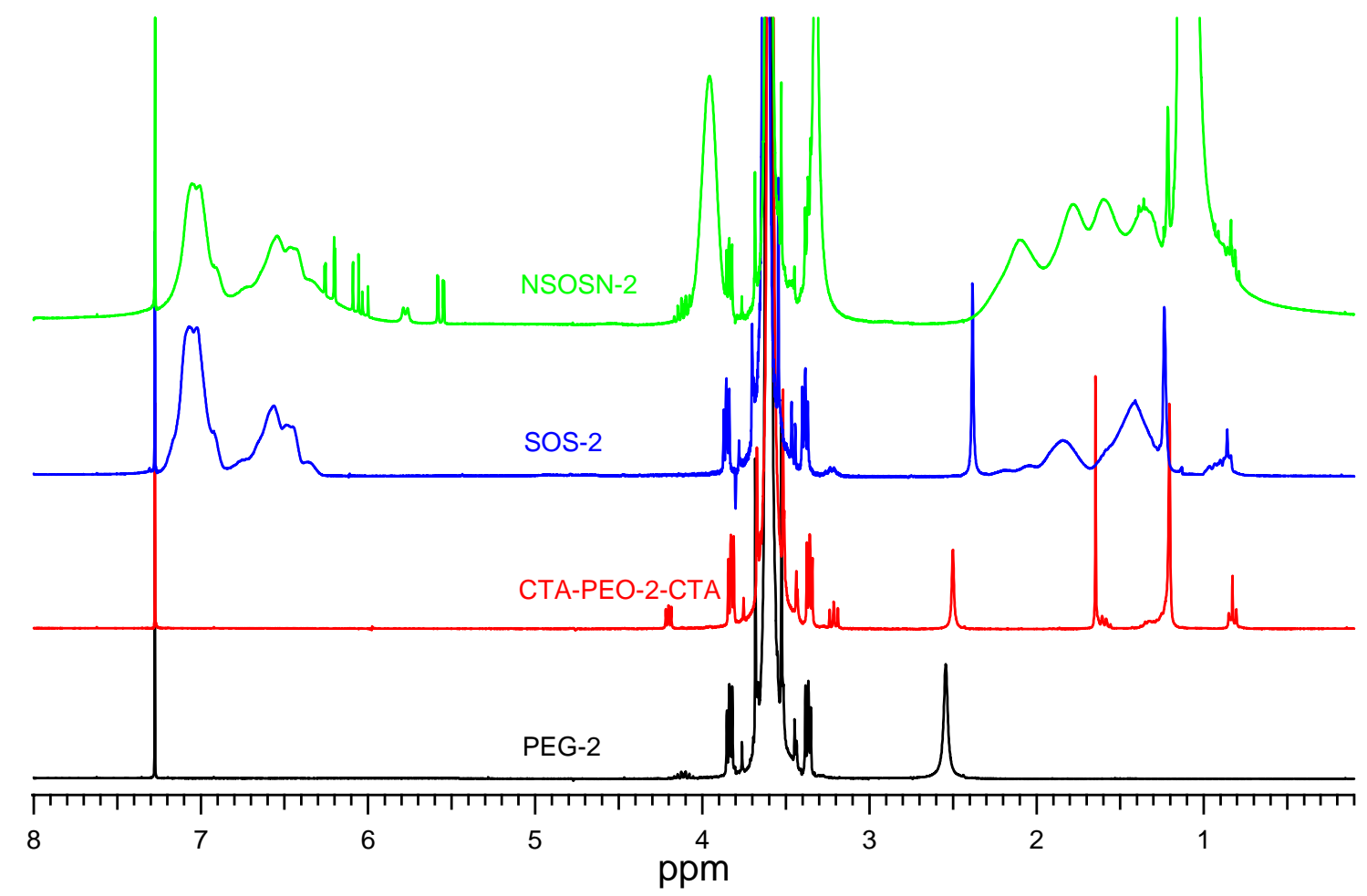

Figure S3. ${ }^{1} \mathrm{H}$ NMR spectra of PEG-2 homopolymer, CTA-PEO-2-CTA macroinitiator, SOS-2 triblock copolymer, and NSOSN-2 pentablock copolymer. 


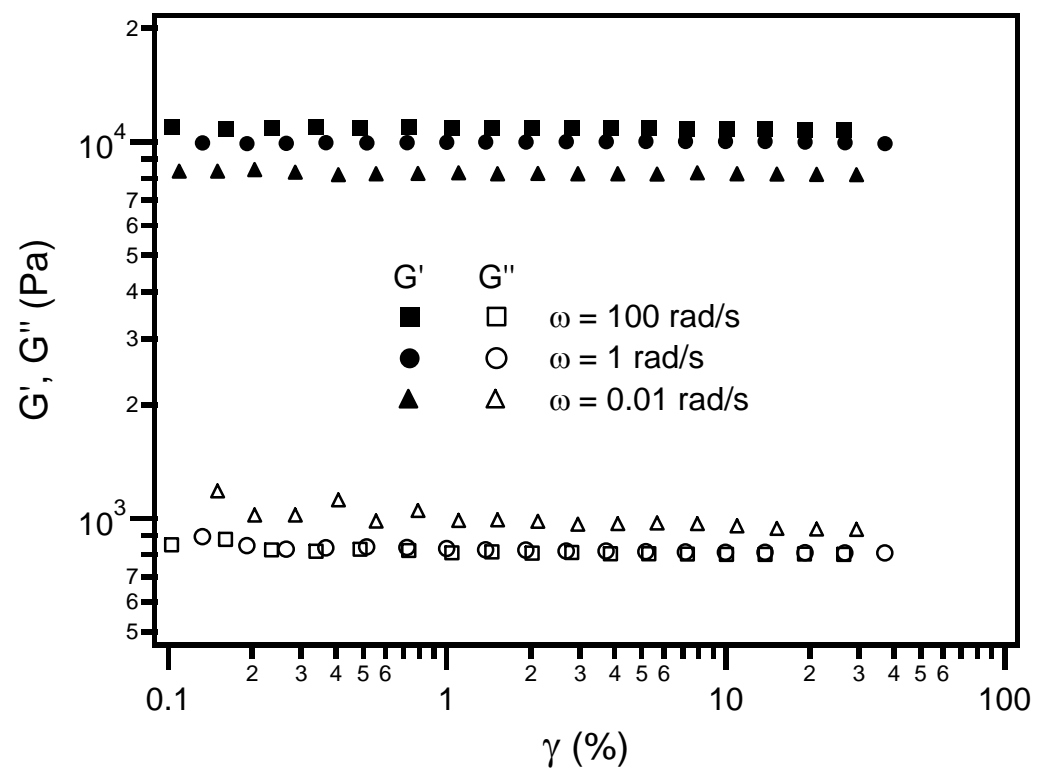

Figure S4. Strain dependences of the dynamic shear moduli $\left(G^{\prime}\right.$ and $\left.G^{\prime \prime}\right)$ for the ion gel with 10 wt\% NSOSN-1, measured at $25{ }^{\circ} \mathrm{C}$ and three indicated frequencies.

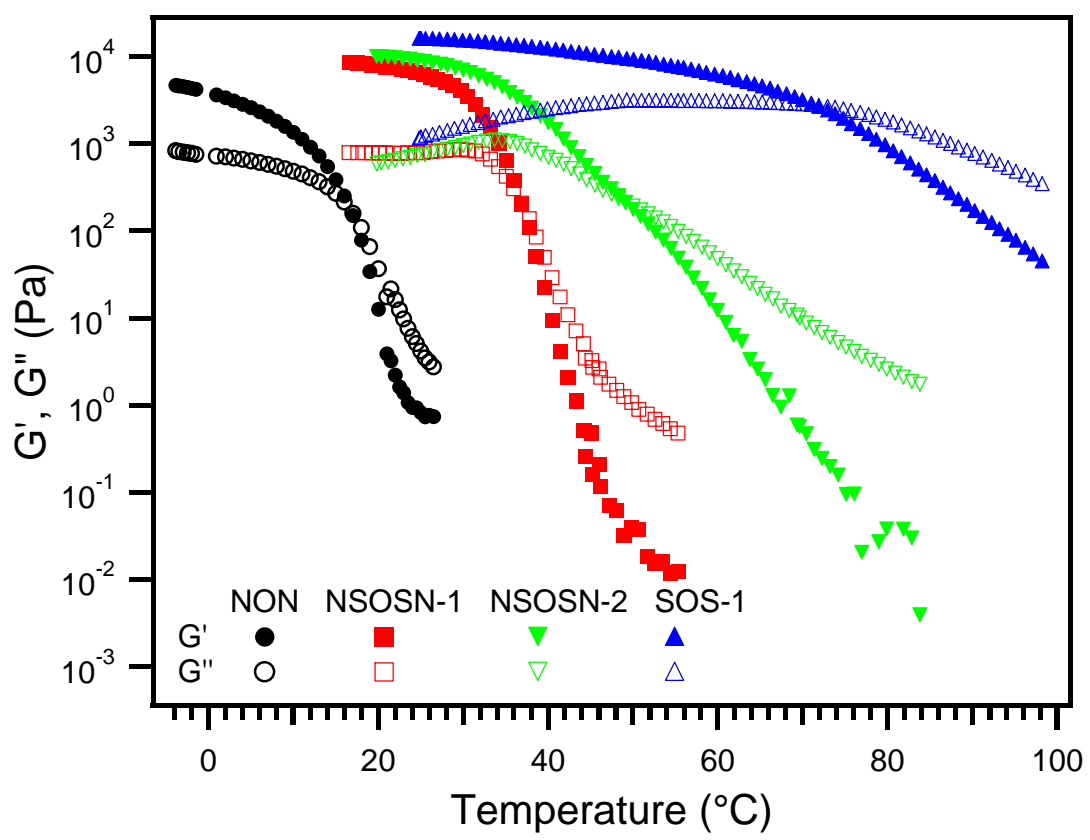

Figure S5. Temperature dependences of the dynamic storage and loss moduli for four ion gels (NON, NSOSN-1, NSOSN-2, and SOS-1, each with $10 \mathrm{wt} \%$ copolymers in [EMIM][TFSI]). The measurements were taken at a strain $\gamma=2 \%$, frequency $\omega=0.1 \mathrm{rad} / \mathrm{s}$, and a heating rate of 1 ${ }^{\circ} \mathrm{C} / \mathrm{min}$. 


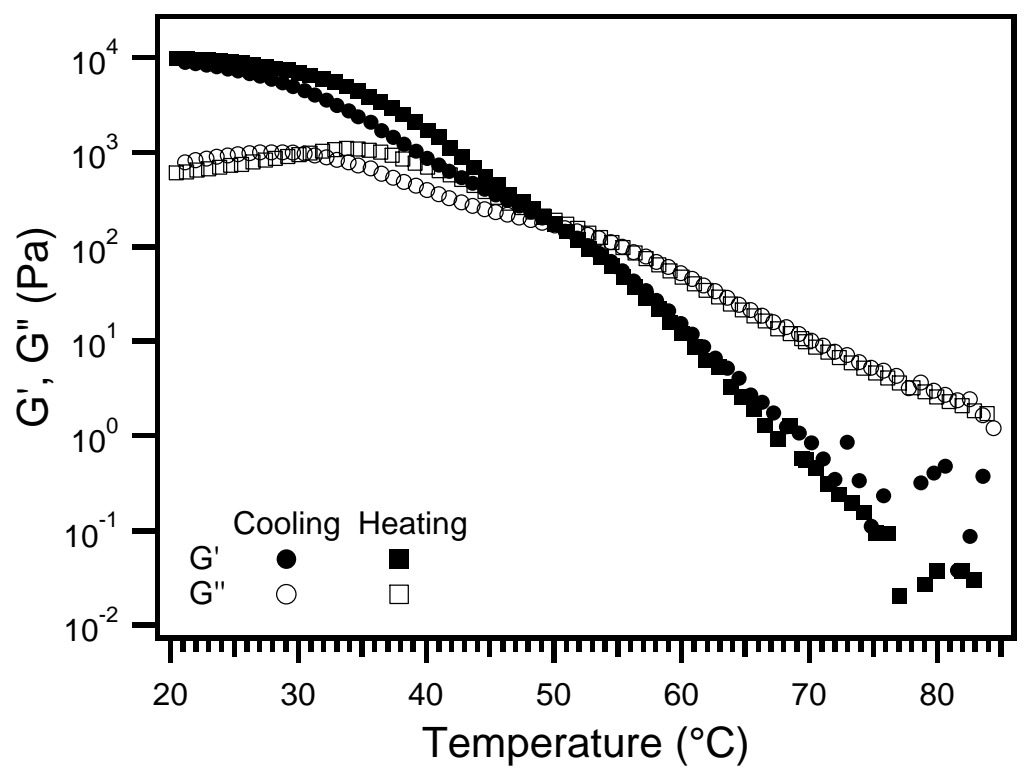

Figure S6. Dynamic shear moduli as a function of temperature in a thermal cycle from heating to cooling for the ion gel with $10 \mathrm{wt} \% \mathrm{NSOSN}-2$. The measurements were taken at a strain $\gamma=$ $2 \%$ and frequency $\omega=0.1 \mathrm{rad} / \mathrm{s}$ with heating and cooling rates of $\pm 1{ }^{\circ} \mathrm{C} / \mathrm{min}$.

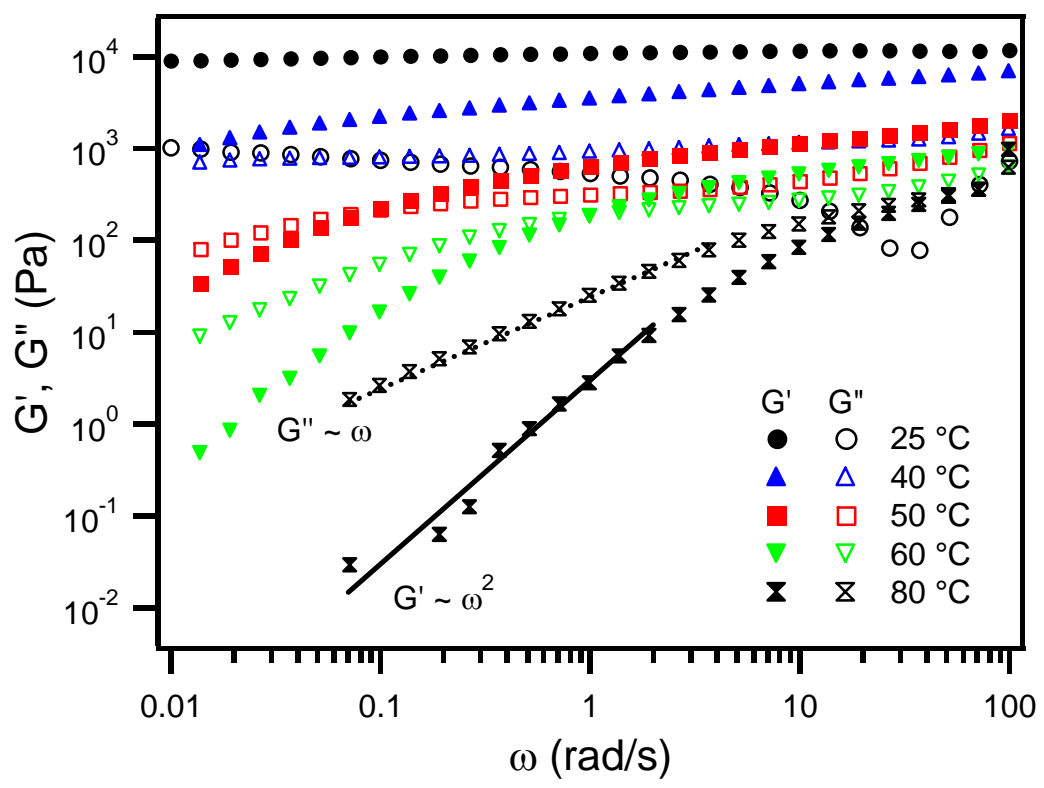

Figure S7. Frequency dependences of the dynamic shear moduli $\left(G^{\prime}\right.$ and $\left.G^{\prime \prime}\right)$ for the ion gel with $10 \mathrm{wt} \%$ NSOSN-2, measured at a strain $\gamma=2 \%$ and five indicated temperatures. The solid lines are power law fits. 


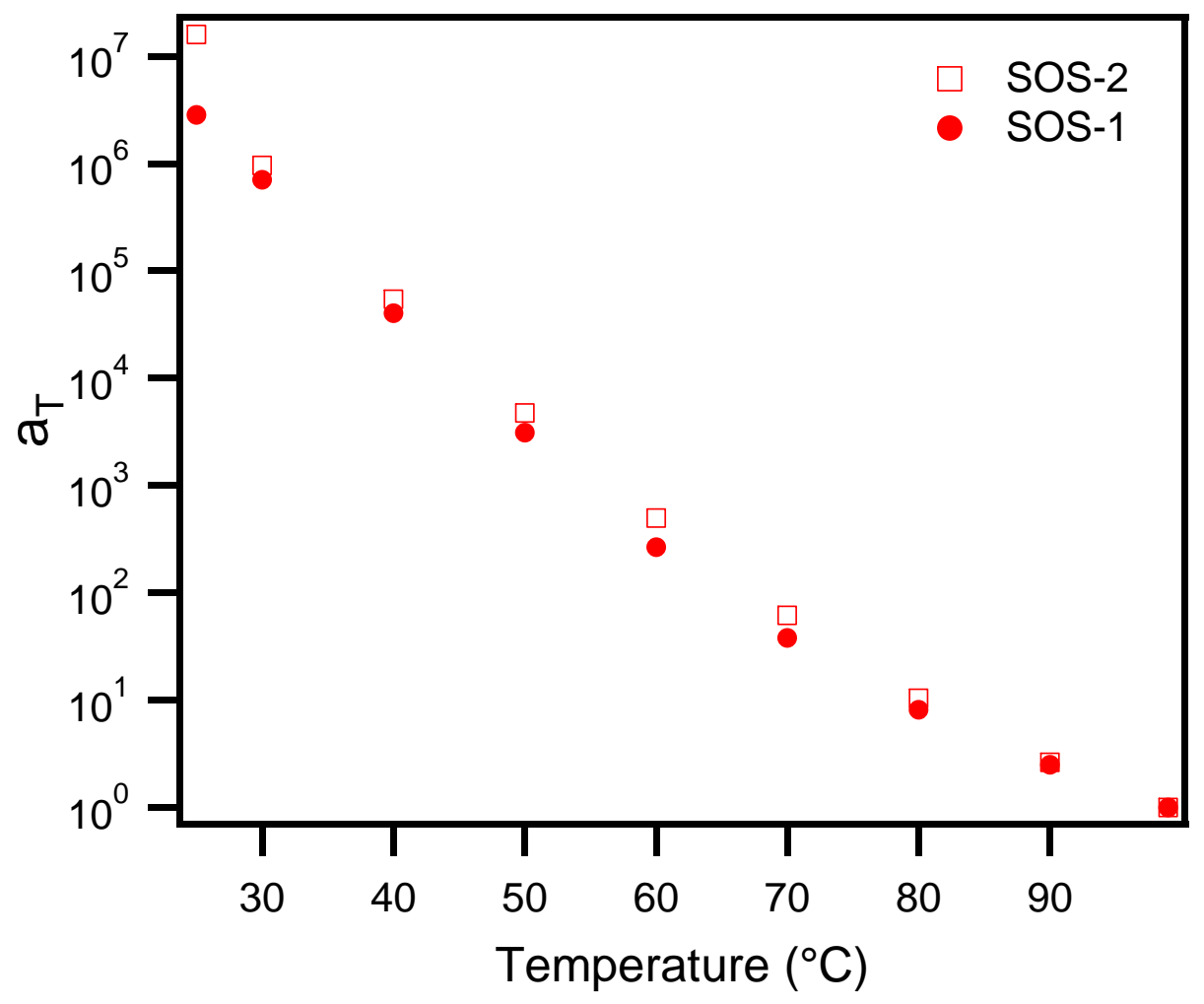

Figure S8. Shift factors for the time-temperature superposition of the slow mode relaxation in the SOS-1 and SOS-2 ion gels with $10 \mathrm{wt} \%$ copolymer. $\left(T_{\text {ref }}=99^{\circ} \mathrm{C}\right)$ 